\title{
Las razones del autor trágico: la dedicatoria de Guzmán el Bueno, de Nicolás Fernández de Moratín
}

Josep Maria Sala Valldaura

\section{Resumen}

A modo de apéndice, edito la dedicatoria de la tragedia Guzmán el Bueno (1777), de Nicolás Fernández de Moratín, que comento en el artículo por su interés como reflexión sobre la teoría y la práctica de este género neoclásico.

\section{Résumé}

L'article propose, en annexe, une édition de l'épttre dédicatoire de la tragédie Guzmán el Bueno (1777) de Nicolás Fernández de Moratín ; il en souligne l'intérêt : l'épître développe une réflexion sur la théorie et la pratique de ce genre néo-classique.

\section{Abstract}

In appendix this paper offers Nicolás Fernandez de Moratin's dedication (1977) to the tragedy "Guzmán el Bueno" ; it emphasizes the interest of this reflection on theory andpractice in that neoclassical literary genre.

\section{Citer ce document / Cite this document :}

Sala Valldaura Josep Maria. Las razones del autor trágico: la dedicatoria de Guzmán el Bueno, de Nicolás Fernández de Moratín. In: Bulletin Hispanique, tome 106, n², 2004. pp. 521-538;

doi : 10.3406/hispa.2004.5201

http://www.persee.fr/doc/hispa_0007-4640_2004_num_106_2_5201

Document généré le 15/06/2016 


\title{
Las razones del autor trágico: la dedicatoria de Guzmán el Bueno, de Nicolás Fernández de Moratín
}

\author{
JOSEP MARIA SALA VAlldaURA \\ Universidad de Lleida
}

L'article propose, en annexe, une édition de l'épître dédicatoire de la tragédie Guzmán el Bueno (1777) de Nicolás Fernández de Moratín; il en souligne l'intérêt : l'épître développe une réflexion sur la théorie et la pratique de ce genre néo-classique.

A modo de apéndice, edito la dedicatoria de la tragedia Guzmán el Bueno (1777), de Nicolás Fernández de Moratín, que comento en el artículo por su interés como reflexión sobre la teoría y la práctica de este género neoclásico.

In appendix this paper offers Nicolás Fernandez de Moratin's dedication (1977) to the tragedy "Guzmán el Bueno"; it emphasizes the interest of this reflection on theory and practice in that neoclassical literary genre.

Mots-clés : Tragédie - Néo-classicisme - Poésie critique - Nicolás Fernández de Moratín.

ARCELINo Menéndez Pelayo fue el primero en lamentar que en la V edición de las Obras de Nicolás y Leandro Fernández de Moratín ${ }^{1}$ se hubieran omitido los prefacios de aquél a sus obras teatrales. Convencido de

1. B.A.E., II, Madrid, Rivadeneyra, 1846; reed. Madrid, Atlas, 1944.

B. $H i ., \mathrm{n}^{\circ} 2$ - décembre 2004 - p. 521 à 538. 
que lleva razón, editamos y comentamos aquí el que abre Guzmán el Bueno ${ }^{2}$ y que sirve como dedicatoria a su descendiente Alonso Pérez de Guzmán el Bueno, duque de Medina Sidonia, traductor de Ifigenia (1768), de Jean Racine, y de Hernán Cortés (1776), de Alexis Piron ${ }^{3}$.

Este prefacio, el último y el más interesante de los que escribiera, merece la atención del historiador del teatro porque en él don Nicolás se defiende de algunas críticas recibidas por su Hormesinda y porque, merced a ello, explica un buen número de las dificultades del escritor de tragedias, lamentando al mismo tiempo el abandono de la política teatral de Aranda por parte de Floridablanca ${ }^{4}$. Nicolás Fernández de Moratín lo redacta con la profundidad, con el conocimiento de causa de quien ha sido durante muchos años un teórico del neoclasicismo y está presentando su tercera tragedia. Creo que el lector de estas líneas podrá verificar, en mis comentarios al texto moratiniano $y$, sobre todo, en la lectura del propio prefacio, la importancia de unas páginas olvidadas: late en ellas la pasión del hombre de teatro que sabe razonar, como muy pocos, sobre el género que defiende y practica.

Algunas afirmaciones de la prefación de Guzmán el Bueno confirman el pensamiento ilustrado de Nicolás Fernández de Moratín: el valor de la amistad 5; la preferencia por el amigo hombre de letras, por encima de «su grandeza y su fortuna» (p. 4); los conceptos, a veces implícitos, de patria, felicidad, etc. Las auctoritates citadas repasan los modelos neoclásicos: Horacio, Virgilio, Ovidio, Salustio, Longino ${ }^{6}$, Justo Lipsio (Joost Lips); o D’Alembert y el abate Fleury, cuya obra «desde Gregorio Mayans y Siscar

2. Nicolás Fernández de Moratín, Guzmán el Bueno, Madrid, Antonio de Sancha, 1777, pp. 2-11. (A partir de ahora, indicaremos la página después de la cita.)

3. Como ha demostrado Francisco Aguilar Piñal, Nicolás Fernández de Moratín «recibió del duque mil quinientos reales "por vía de gratificación de la impertinencia que tuvo en releer y limar la traducción hecha por S.E. del francés al castellano" (Archivo Ducal, leg. 3801)" (Introducción al Siglo XVIII, t. 25 de R. de la Fuente, ed., Historia de la literatura española, Madrid, Júcar, 1991, p. 40).

4. Remito a mi artículo "Lucrecia, la primera tragedia de Nicolás Fernández de Moratín», en Estudios dieciochistas en homenaje al profesor José Miguel Caso González, Oviedo, I.F.E.S. XVIII, 1995, II, pp. 295-305; esp., para la evolución de Moratín como autor trágico, pp. 295-297.

5. Escribe en su "Oda al duque de Medina Sidonia»: «El corazón me clavas. / Porque eres la mitad del alma mía, / Y me la tiene tu aflicción confusa: / Acorde unión, sagrada simpatía / / De la divina musa" (Poesías, en Nicolás y Leandro Fernández de Moratín, op. cit., p. 37).

6. Su Tratado de lo sublime había sido vertido al español por Valderrábano (Madrid, $1770)$. 
hasta Jovellanos, formará parte de la biblioteca de un ilustrado cristiano" ${ }^{7}$. Sin embargo, las consideraciones más interesantes para nuestro cometido son las que aluden a la teoría y la práctica de la tragedia. Ya la cita inicial de Guzmán el Bueno, anterior a la dedicatoria y al prefacio, pone de manifiesto hasta qué punto Moratín padre estaba interesado en la nacionalización ambiental y temática de la tragedia: "Vestigia Græca / Ausi deserere, et celebrare domestica / Facta», transcribe del Arte poética de Horacio.

Como sabemos, el interés del escritor madrileño coincide con el que dio lugar a una serie de "tragedias publicadas más o menos bajo la égida del nuevo presidente del Consejo de Castilla, conde de Aranda, por los dramaturgos de la generación a veces llamada "arandina"», y tal florecimiento de "dramas que exaltan las hazañas de héroes nacionales es inseparable de los esfuerzos del gobierno de Carlos III por la regeneración del país» ${ }^{8}$.

La justificación de tratar en el género trágico ambientes y episodios nacionales se hallaba también en las preceptivas. Luzán y Montiano habían preparado el camino, y, de acuerdo con el "celebrare» de Horacio, Nicolás Fernández de Moratín "celebra», en la tragedia que dedica a un descendiente del protagonista, «una acción grande y heroica sobre cuantas celebran otras naciones» (p. 3), para añadir y concretar casi al final, con una pcrsuasoria dubitación:

He procurado guardar el carácter de cada héroe, insinuando algunas formulas y costumbres de nuestros abuelos, de las que deseo ser un insigne anticuario, más bien que de otras naciones que poco o nada nos interesan: no sé si es culpable este patriotismo (pp. 10-11).

Por no citar, entre bastantes, el prólogo de Jovellanos a su Pelayo o, incluso, a Meléndez Valdés y Forner, conviene repasar la carta XVI, en la que Nuño -y Cadalso- asocian el concepto de "patriotismo" con el recuerdo de sus «varones ilustres», entre los cuales (el Cid, Fernando III, Gonzalo Fernández de Córdoba, Hernán Cortés...) no faltan ni Pelayo, el libertador, ni Alonso Pérez de Guzmán, «ejemplo de fidelidad» '. El héroe de Tarifa (1256-1309) había merecido un largo reconocimiento en las

7. Francisco Sánchez-Blanco, Europa y el pensamiento español del siglo XVIII, Madrid, Alianza, 1991, p. 312.

8. René Andioc, Teatro y sociedad en el Madrid del siglo XVIII, Madrid, Fundación Juan March - Castalia, 1976, p. 385.

9. José Cadalso, Cartas marruecas (con Noches lúgubres), ed. de Emilio Martínez Mata, Barcelona, Crítica, 2000, carta XVI, p. 59. 
letras españolas ${ }^{10}$; según Jovellanos, era "un segundo Bruto» ${ }^{11}$, en total consonancia con la conducta y las palabras políticas de este personaje en la Lucrecia, del propio Moratín; y permitía un claro paralelo entre las estatuas y los héroes de Roma con los de España, si tenemos en cuenta la comparación última de la carta de Nuño: «a semejantes ardides [estatuas e historia de sus héroes] debió Roma en mucha parte el dominio del orbe» ${ }^{12}$.

La introducción de Guzmán el Bueno se construye mediante la alternancia de juicios positivos y constataciones críticas harto negativas del contexto teatral. Amparándose en Horacio (y Casio Longino), Nicolás Fernández de Moratín arremete contra «los crítico-poetas teóricos que en su vida han hecho un verso, y sin la práctica se creen jueces suficientes en un arte tan difícil, por sólo haber leído una o mil Poéticas» (p. 5). Lo hace desde el orgullo de quien se considera doblemente autorizado por ser poeta y retórico, para emplear palabras del propio prefacio, defendiéndose de quienes habían arremetido contra su Lucrecia o su Hormesinda. El más severo, Ramón de la Cruz, se había valido precisamente de algunos de los argumentos retomados por Moratín:

¿Qué respeto han de causarme unos críticos, que ponen el mayor cuidado en la ocultación de sus nombres y apellidos; unos ingenios, que escriben a escote; unos autores, que, reconvenidos, niegan sus obras; y, últimamente, unos críricos, que el primer año sólo produjeron un sainete con idea, método y pensamientos, que antes había publicado otro [Francisco Mariano Nifo] y el segundo después de muchos meses de trabajo, dos de elogios preparativos para inflamar las gentes, uno de rigurosos ensayos; $y$, al fin, con tres cartas y un proceso de recomendaciones, presentaron al mundo la monstruosa y detestada tragedia Hormesinda ${ }^{13}$ ?

10. Véase Isabel Millé Jiménez, "Guzmán el Bueno en la historia y en la literatura», Revue Hispanique, 78 (1930), pp. 311-486.

11. Así lo recuerdan R. Andioc, op. cit., p. 389; y Francisco Sánchez-Blanco, «Guzmán el Bueno, ¿un arquetipo para el hombre ilustrado? Tratamiento dramático de un mito nacional", en Siegfried Jüttner, ed., Spanien und Europa in Zeichen der Aufklärung. Internationales Kolloquium an der Universität-GH-Duisburg vom 8.-11. Oktober 1986, Frankfurt, Peter Lang, 1991, p. 228. En efecto: en 1776, la "Carta de Jovino a sus amigos salmantinos" dice: "Vea la escena / al inmortal Guzmán, segundo Bruto, / inmolando la sangre de su hijo, / de su inocente hijo, al amor patrio...) (Poesía española del siglo XVIII, ed. de Rogelio Reyes, Madrid, Cátedra, 1988, p. 344, w. 323-326).

12. Op. cit., p. 60.

13. En casa de nadie, no se meta nadie o El buen marido, zarzuela semi-jocosa en dos actos, Biblioteca Municipal de Madrid, I 4,4. Olim 1-91-10 (autógrafo, 1770); cit. por Emilio Cotarelo y Mori, Iriarte y su época, Madrid, Rivadeneyra, 1897, p. 86. 
Con todo, Moratín el Viejo se debió sentir especialmente dolido por los reproches de Tomás de Iriarte, tan «fiel a las teorías clasicistas de inspiración italo-francesa" ${ }^{14}$, quien tilda de "crédulo" al Pelayo de Hormesinda ${ }^{15}$. De ahí la larga defensa, basada en que hay que disimular los defectos si son discutibles y si la obra tiene, por lo demás mérito:

Por no reparar en esto, juzgaron algunos críticos que en mi Hormesinda hice crédulo a Pelayo, como si la verosimilitud dramática fuera lo mismo que la física, o como si una tragedia fuera algún pleito ordinario, o un teatro un tribunal (pp. 5-6).

Con toda seguridad, don Nicolás recordaba la diferencia aristotélica entre la fábula trágica y la historia, aunque ambas partieran de hechos reales tanto en el caso de Hormesinda como en el de Guzmán el Bueno. Moratín sabía que «el poeta inventa a su gusto y conforme es más conveniente para su intento", adapta los sucesos "a las reglas del teatro" y crea "los genios que reparte entre las personas" ${ }^{16}$. Y de ahí que piense en una fábula moral y no física.

Esta libertad de la ficción alcanza, para el escritor madrileño, la imitación de la naturaleza, lo que no contradecía a Aristóteles ni a buena parte de los preceptistas del Dieciocho ${ }^{17}$. Respeta, por supuesto, el decoro, y, separando horacianamente naturaleza y violencia, prefiere que Lucrecia, en la tragedia homónima, se suicide fuera del escenario, aunque «según los varios genios, uno juzga natural lo que a otro le parece violento" (p. 6). Con lo cual nos viene a decir que se le aplique el beneficio de la duda en materia de imitación y verosimilutud. No hay duda, además, de que menciona el término violencia porque le preocupa su tratamiento en escena: se opone a su exhibición, contrariamente al gusto predominante (un gusto que arrastró al mismísimo López de Ayala en su primera versión de Numancia destruida) ${ }^{18}$. El haber prescindido de montar sobre el tablado una «ejecución

14. Giuseppe Carlo Rossi, Estudios sobre las letras en el siglo XVIII, Madrid, Gredos, 1967, p. 106.

15. Véase la "Carta» en Emilio Cotarelo y Mori, op. cit., p. 433ss.

16. Ignacio de Luzán, La Poética. Reglas de la poesía en general y de sus principales especies, ed. de Russell P. Sebold, Barcelona, Labor, 1977, libro III, cap. III (V), p. 441.

17. Remito a la síntesis de José Checa Beltrán, Razones del buen gusto. (Poética española del neoclasicismo), Madrid, C.S.I.C., 1998, pp. 78-108.

18. Valga, a modo de ejemplo, la opinión coetánea de Francisco Antonio de Mallent Portocarrero: «no se me ofrece dificultad en que se vean ejecutadas ambas muertes con 
aparatosa» puede ser -según Andioc- «una de las razones por las que el público mostró poco entusiasmo ante el Guzmán de Moratín» ${ }^{19}$.

Después de Horacio, Nicolás Fernández de Moratín va a recurrir a Platón, al proseguir en su prefación:

y las más veces proviene de que leen a sangre fría lo que el poeta escribió encendido y muy agitado, y son pocos los que pueden imaginar las situaciones sublimes y hacer con viveza en su fantasía lo que llaman composición de lugar (p. 6).

Subyace, sin duda, el impetus ille sacer, de Ovidio, o ese deus in nobis que permite la furor de los creadores, "poseídos cada uno por el dios que lo posee", ya que el poeta inspirado compone "sin tener clara la mente», "con el dios dentro y el juicio fuera y la razón lejos» ${ }^{20}$. Nicolás Fernández de Moratín está defendiendo su obra desde la confianza en haber sido fiel a la "naturaleza general», puesto que cree en la imitación fantástica, a la manera de Platón. Según Ignacio de Luzán, tal imitación

comprehende todo lo que, no existiendo por sí, tiene nuevo ser y vida en la fantasía del poeta, cuando inventa nuevas cosas o acciones semejantes a las históricas, no sucedidas, pero que pueden suceder. Y como de la icástica es objeto la verdad, así de la fantástica lo es la ficción ${ }^{21}$.

Incluso Montiano había precisado que "el arte corrige la naturaleza» 22.

Por estas altas razones, frente a quienes reparan en "quisquillas gramaticales», justifica haber adornado la acción de Guzmán el Bueno «de varios incidentes a propósito, que la hacen resaltar más y forman los indispensables episodios» (p. 7). Para Nicolás Fernández de Moratín, que ha comprendido bien a Aristóteles, Platón y Horacio, la teatralidad es un valor que supera el de la exactitud histórica, y que permite incluso las licencias y los errores que

diversas circunstancias a presencia de los espectadores, por cuanto se forma de este modo la acción más teatral, cuyo objeto debe ser el alma de todas las composiciones dramáticas" («Prefacción», Marco Attilio Regulo. Tragedia en Tres actos, Cádiz, Manuel Espinosa de los Monteros, Impresor de la Real Marina, 1777).

19. Op. cit., p. 83.

20. Platón, Ibn, 534. (Pone este parecer en boca de Sócrates.)

21. Op. cit., lib. I, cap. VIII [IX], p. 170.

22. Discurso II sobre las tragedias españolas, en Ataulpho, Madrid, Imprenta del Mercurio, por Joseph de Orga, 1753, p 94. 
se subsumen bajo el acierto teatral general. No se expresaba de distinto modo Ignacio de Luzán, quien por otra parte llegaba a subordinar el teatro a la política, en su sentido dieciochesco, tan moral. Es más: en clara diferenciación con el teatro escrito para ser leído (Montiano, Juan José López de Sedano), Moratín padre concede a la representación un papel nuevo, al afirmar que «es menester tropezar con quien sepa disponer el teatro, y entonces no le faltará verosimilitud ni visualidad» (p. 8). La asociación de las dos palabras finales, verosimilitud y visualidad, y el papel que otorga a la escenificación como tarea colectiva revelan, en mi opinión, tal novedad y el agudo sentido teatral de Nicolás Fernández de Moratín, neoclásicamente enamorado del «mágico y dulce encanto que resulta de la ilusión teatral» ${ }^{23}$.

En la jerarquización de los valores estéticos al servicio de los morales, destaca asimismo la máxima estima que el autor tiene por la belleza -necesaria para el deleite $y$, pues, para la utilidad-, belleza que enlaza con lo teatral, y sitúa por encima «de la exactitud árida y escrupulosa que prescriben las reglas» (p. 7). De acuerdo con las cuestiones que a renglón seguido aborda en el prefacio, de las acciones, las costumbres, la sentencia y la dicción -las "cuatro clases de belleza ideal»- ${ }^{24}$, parece interesarse especialmente por el argumento (más concretamente, por la verosimilitud de la sintaxis dramáticonarrativa) y por el lenguaje. No constituyen, por supuesto, una excepción a las preceptivas clásicas y neoclásicas ni la consideración superior de lo bello -pues lo verosímil y las reglas sirven a la belleza, que es conectada con la naturaleza-, ni siquiera la generosa atribución que concede a «los hombres grandes», los cuales pueden interpretar las reglas y modificar las leyes. La novedad de su planteamiento estético radica en el énfasis con que asocia la «teatralidad» con la «belleza»: «Muchos errores que verdaderamente lo son, los cometen los autores dramáticos con pleno conocimiento, cuando son muy teatrales, quiero decir, cuando de ellos resultan mayores hermosuras" (pp. 6-7). Aunque después afirme el carácter esencialista, no circunstancial de los preceptos neoclásicos: el poeta juicioso sabe las reglas «por lo menos tan bien como sus

23. Desengaño II al teatro español Madrid, s.i., 1762, p. 21. (Hay ed. modcrna: La Petimetra. Desengaños al teatro español. Sátiras, ed. de David T. Gies y Miguel Ángel Lama, Madrid, Castalia, 1996.)

24. Esteban de Arteaga, Investigaciones filosbficas sobre la Belleza ideal considerada como objeto de todas la Artes de imitación, en Obra castellana. La belleza ideal. Escritos menores, ed. de Miguel Batllori, Madrid, Espasa Calpe, 1972, 3a ed. rev., cap. V, p. 54. 
críticos» y "para haberlas abandonado en parte (que en lo esencial no es posible) no le habrán faltado motivos» (p. 7).

En el caso particular de la unidad de lugar, por ejemplo, Nicolás Fernández de Moratín asevera en relación con la tragedia que prologa:

Guzmán el Bueno no está quebrantada, aunque se representa el suceso en el muro y acampamento, porque el auditorio se supone estar en el adarve de Tarifa, desde donde oye y ve cuanto pasa en ambas partes bien contiguas (pp. 7-8).

La verosimilitud depende en última instancia de la disposición del teatro, del escenario y el patio; entendida de esta manera es como la guarda también López de Ayala en Numancia destruida, con la seguridad de no infringir precepto alguno. Al abrigo de Jerónimo Barufaldi, Luzán proponía mejorar la verosimilitud «siendo el lugar uno, estable y fijo, aunque dividido en partes que serían contiguas» ${ }^{25}$.

En el caso de la unidad de tiempo, apenas la alude en este prólogo. En realidad, lo más interesante que Nicolás Fernández de Moratín escribió sobre este precepto parte de su reflexión sobre la verosimilitud y ya había sido formulado anteriormente:

El drama no refiere cosa como pasada, sino que la pone en acción sobre el teatro como presente, para hacer creer al auditorio que es verdad lo que está oyendo; y para esto es indispensable que no represente cosas imposibles de suceder, pues de lo contrario percibe el engaño. ${ }^{26}$

Por tanto, ya en el primero de los Desengaños al teatro español, Nicolás Fernández de Moratín subordinaba las reglas a la verosimilitud, concibiendo el teatro como representación. Forner en Los gramáticos. Historia chinesca, Jovellanos, Leandro Fernández de Moratín («los preceptos deben ilustrar y dirigir al talento, no esterilizarle ni oprimirle») 27 sostuvieron la misma opinión. También Francisco Mariano Nifo.

En el ámbito teórico habían hallado un fructífero equilibrio entre naturaleza y arte ${ }^{28}$; pero, sin que confundieran la tragedia con un pleito ordinario ni el teatro con un tribunal -para volver a las palabras de Moratín padre-, la instrumentalización utilitarista del género fue tal que se acercó

25. Op. cit., lib. III, cap. V (VII), p. 466.

26. Desengaño al theatro español: respuesta al Romance liso y llano y defensa del Pensador, [Madrid], s. i., s. d. [1762], p. 50.

27. Obras póstumas, Madrid, Rivadeneyra, 1867, I p. 79.

28. R. Andioc, op. cit., p. 536. 
demasiado a las circunstancias del presente lo que requería una mayor distancia. Por ejemplo, Lucrecia terminaba con el deseo de servir «a los siglos de escarmiento", y en su prefacio se abogaba ya, muy al modo de Luzán, por una tragedia como escaño o púlpito político y moral, "para purgar el ánimo de las pasiones violentas que le arrastran a su precipicio y para enamorar a los hombres de la virtud y enseñarlos a ser héroes» ${ }^{29}$.

El hecho de relegar el amor a un papel muy secundario de la acción o, al menos, del tema, corrobora esa simplificación de algunos autores trágicos neoclásicos, demasiado comprometidos en la defensa del absolutismo o de la nobleza como buena consejera del rey y buena conductora del pueblo ignorante y a veces enloquecido. Sin embargo, en Guzmán el Bueno, el amor está presente desde una perspectiva poco usual, la paternofilial, y permite extraer la heroica, noble virtud de supeditar la felicidad familiar, incluso la naturaleza de los afectos paternos, al bien común, a la política. El acierto de Nicolás Fernández de Moratín estriba en que ni escamotea ni superficializa el tema amoroso, cuestión sobre la que, evidentemente, ha reflexionado y sobre la que declara: en Guzmán el Bueno, el amor es «decente, es accesorio y es trágico, que es cuanto hay que responder" (p. 11). Sin duda, no convenía que los sentimientos individuales predominaran sobre las necesidades de la sociedad, que Guzmán el Bueno hubiera dejado de obedecer según su condición de vasallo leal o que Aluro hubiera podido ser feliz con la protagonista de Numancia destruida. No se olvide que en el Dieciocho todavía el noble ha de saber controlar el amor:

BRUTO.[...] Que aunque reine en el pecho enamorado

De la hermosa consorte regalada

El tierno afecto, dulce y verdadero,

$\mathrm{El}$ amor a la patria es lo primero ${ }^{30}$.

La defensa de la actitud estoica como propia del heroísmo acerca la obra de Nicolás Fernández de Moratín a la de Corneille, pero, por su radical rotundidad, la aleja del público al que se dirigía. En todo caso, Guzmán el Bueno asienta el pacifismo y la concepción militar del pensamiento ilustrado ${ }^{31}$ en el estoicismo, gracias a reducir la unidad de acción «a la

29. Lucrecia, Madrid, Impr. de Joseph Francisco Martínez Abad, 1763.

30. Lucrecia, en Nicolás y Leandro Fernández de Moratín, Obras, acto II, esc. VII, p. 109a.

31. Remito a Francisco Sánchez-Blanco, art. cit., p. 228ss.; y a Andioc, para quien el Guzmán ues la versión militar -más que guerrera- del perfecto ciudadano tal como lo concebían los partidarios del poder centralizado" (op. cit., p. 388), y uel héroe oficial que el 
resistencia y constancia de aquel heroico español» (p. 7). Se trata de «un llamamiento claro a la aristocracia a constituirse en modelo social y a asumir su función en la vida política y militar de la patria» ${ }^{32}$, es decir, «una ética de la responsabilidad pública» ${ }^{33}$, que Moratín el Viejo comparte con Trigueros o López de Ayala.

El papel del amor en la tragedia era tenido en cuenta en el primero de los dos Discursos sobre las tragedias españolas, el de 1750, de Agustín de Montiano. El vallisoletano, autor asimismo de otra obra sobre la nobleza "goda» (Ataúlfo), cita el encabezamiento de Sémiramis, donde Voltaire se declara contrario al amor en la tragedia. Todo ello lo conocía don Nicolás, al igual que la relevancia que el amor poseía en las obras anteriores sobre el suceso de Tarifa: "Como la hazaña del señor don Alonso fue tan admirable, que aun se emplearon muchas plumas extranjeras, como la de Justo Lipsio y otras, no es mucho que la tratasen nuestros ingenios españoles» (p. 10). En efecto, los dramas de Juan Claudio Hoz y Mata y de Antonio de Zamora se centran en el amor, pero el eslabón más cercano a Moratín es El cerco de Tarifa o Los Guzmanes, de Cándido María Trigueros, escrita en $1768^{34}$.

Nicolás Fernández de Moratín escribió en 1775 la comedia La defensa de Melilla, hoy perdida, "a instancia del Duque de Medina Sidonia» 35. Según Aguilar Piñal ${ }^{36}$, también instó a Trigueros a que redactara la tragedia sobre su antepasado, y no sé hasta qué punto es pecar de malicioso establecer alguna conexión entre los intereses exclusivamente literarios de los duques y los más particulares de la casa de los Medina Sidonia. Sánchez-Blanco señala que los duques

mueven en 1739 un pleito para que se les renueve el "privilegio de las almadrabas", por el cual gozaban de los impuestos que recaían sobre la

despotismo ilustrado propone a la admiración e imitación de los españoles: un individuo capaz de dominar sus impulsos naturales, sus sentimientos, de alienar, en una palabra, parte de su personalidad en beneficio de la patrian(ibid., pp. 292-293).

32. Jesús Pérez Magallón, El teatro neoclásico, Madrid, Eds. del Laberinto, 2001, p. 117.

33. Francisco Sánchez-Blanco, El Absolutismo y las Luces en el reinado de Carlos III, Madrid, Alianza, 2002, p. 153.

34. La obra anónima Guzmán y Arlaxa probablemente está más cercana en el tiempo al melólogo Guzmán el Bueno (1791), de Tomás de Iriarte. No nos ha llegado Guzmán (1780), de Enrique Ramos.

35. Jerónimo Herrera Navarro, Catálogo de autores teatrales del siglo XVIII, Madrid, Fundación Universitaria Española, 1993, p. 182.

36. Un escritor ilustrado: Cándido María Trigueros, Madrid, CSI - Instituto de Filología, 1987, pp. 190-192. 
actividad pesquera en las costas andaluzas. Para justificar sus pretensiones, desempolvan todos los documentos antiguos que hacen referencia a la donación de esos privilegios a los sucesores de aquel Guzmán el Bueno, defensor de Tarifa ${ }^{37}$.

En cualquier caso, de modo muy distinto a Moratín padre, Trigueros introduce amores "para aumentar el pateticismo y hacer resplandecer la virtud de la constancia heroica» ${ }^{38}$.

Por otra parte, las referencias al lenguaje de su Guzmán el Bueno redundan tanto en la habitual crítica a la corrupción del español por los traductores como en la tópica consideración de su "grandeza y sublimidad" (p. 8). Implícitamente, estos dos sustantivos dan la razón una vez más a los defensores de la aptitud para la tragedia de la lengua castellana, en un contexto más general de preocupación por la proprietas del idioma, que don Nicolás comparte con otros muchos neoclásicos: Jovellanos, Forner, Vargas y Ponce, Tomás de Iriarte, Cadalso... ${ }^{39}$.

Sin duda, el casticismo lingüístico recibía con prevención las traducciones, y hasta Jovellanos teme el contagio en el prólogo de su Pelayo:

En cualquier composición se debe observar cuidadosamente la pureza del idioma, y siempre es defecto reprensible afectar en el estilo cierto aire de lengua extraña, pero hay gentes tan escrupulosas en estas materias $[\ldots]]^{40}$.

En las ya citadas Cartas marruecas, concretamente en la XLIX y la L, Cadalso animaba a traducir libros científicos porque no ponían en peligro el castellano, dada la general afinidad léxica y sintáctica en matemáticas, física, etc. Leandro Fernández de Moratín repite las mismas ideas de su padre a propósito de quienes,

ignorantes de su propio idioma, [...] creyeron hallar en las obras extranjeras toda la instrucción que necesitaban para satisfacer su impaciente deseo de ser autores. Hiciéronse poetas, y alteraron la sintaxis y propiedad de su lengua, creyéndola pobre ${ }^{41}$.

37. Art. cit., p. 232.

38. "Carta del autor al Sr. Dn. P.O. [Pablo Olavide] (que sirve de Prólogo)", El cerco de Tarifa o Los Guzmanes, ms. en la Biblioteca Menéndez y Pelayo de Santander (M 38).

39. Fernando Lázaro Carreter, Las ideas lingüisticas en España durante el siglo XVIII, Barcelona, Crítica, 1985, p. 235ss.

40. Obras, B.A.E. XIVI, Madrid, Rivadeneyra, 1858, p. 51.

41. Discurso preliminar a las Comedias, en Nicolás y Leandro Fernández de Moratín, Obras, p. 234. 
Insiste, don Leandro, sobre este particular en La derrota de los pedantes, sin llegar a las exageraciones de un Forner: «Hacer versos hoy en España equivale a encadenar dicciones y cláusulas medio francesas» ${ }^{42}$. El tema, pese a todo, distaba de concitar una opinión unánime, y hay que destacar, como ya hiciera Menéndez y Pelayo, que Antonio de Capmany se lamentaba de la pobreza del castellano y defendía «la noble libertad de algunos traductores en valerse de ciertos rasgos brillantes y expresivos de otra lengua para hermosear la nuestra» 43 .

Nicolás Fernández de Moratín conocía, muy probablemente, las ideas de Capmany, pues coinciden la introducción a Guzmán el Bueno y el prólogo del Arte de traducir el idioma francés al castellano (1776); en aquélla se pregunta: "Pero quien en la suya [en su lengua] no es poeta ni retórico, ¿cómo lo ha de ser en otra, que siempre se sabe menos que la materna?» (p. 8), y en éste se hacía otro tanto, con la misma formalización: «Si los primores de nuestra propia lengua sólo a fuerza de un continuo y atento estudio se pueden conocer, ¿cuánta penetración pedirán los de una lengua extranjera?» 44 .

De todos modos, Nicolás Fernández de Moratín no podía sospechar que la competencia lingüística de las traducciones «arandinas» afectaba menos la pureza del lenguaje castellano que la parcial lectura con que las abordaban socavaba el propio género sublime. I. L. McClelland ${ }^{45}$ escribió páginas muy inteligentes sobre las carencias traductoras de los amigos de Olavide: las incomprensiones ideológicas, los cambios de intensidad e implicación, la conversión de personajes en planos, la potenciación de la "historia» sobre el pensamiento... Y, desde luego, cierto acercamiento de afán moralizador a los ideales del propio círculo, so pretexto a veces de conseguir la licencia para publicar o estrenar.

$\mathrm{Al}$ igual que en la cuestión lingüística, no hay demasiada novedad en el prólogo de Guzmán el Bueno acerca del contexto teatral de la obra y sus posibilidades de acogida: «Bien sé que esta tragedia no es para los teatros de

42. Exequias de la lengua castellana, Madrid, Compañía Ibero-Americana de Publicaciones, s. a., p. 104.

43. Apud Marcelino Menéndez y Pelayo, Historia de las ideas estéticas en España, Madrid, Plus-Ultra, 1923, VI p. 63.

44. Antonio de Capmany y Surís de Montpalau, Arte de traducir el idioma francés al castellano, Madrid, Antonio de Sancha, 1776, p. V. (Hay ed. facsímil, ed. por M. Carmen Fernández Díaz, Santiago de Compostela, Universidade de Santiago de Compostela, 1987.)

45. Spanish Drama of Pathos 1750-1808, Liverpool, Liverpool University Press, 1970, I p. 169ss. 
hoy día, donde sólo reina la abominación y la barbarie, y no tienen de ello la culpa los ingenios españoles» (p. 11). Aparte de defender la literatura nacional anterior, característica común de todos los neoclásicos (por mucho que a veces se tergiverse su visión historiográfica), Moratín padre recuerda con alguna amargura las dificultades para estrenar su Hormesinda y, sobre todo, pone de manifiesto su ambición innovadora, frente a la corrupción -el paralelismo con el tema del lenguaje es evidente- de la escena española coetánea, carente de decoro.

El término «barbarie» (o el adjetivo «bárbaro») aparece a menudo en la pluma de los neoclásicos ${ }^{46}$, estableciendo así una clara diferenciación respecto a lo que deseaban aportar: la "razón natural» en favor de la «felicidad de todos», contra el «desatino», la «barbarie» o la «falta de decoro» teatrales. En la prefación de Jahel, de Juan José López de Sedano, se leía:

en España no se escriben tales obras para representarse, ni son compatibles con las monstruosidades que tienen tomada la posesión de sus teatros, en donde se abomina y del todo se ignora lo que es arte, regularidad y buen gusto, y sólo reina la confusión, la indecencia, el pedantismo y la última barbarie, sostenidos de una antigua, vergonzosa y mal tolerada costumbre ${ }^{47}$.

Este pasaje del riojano, al igual que aquel diagnóstico del madrileño, se integran en una misma cadena de juicios adversos contra el estado del teatro, y la mención del «buen gusto», frente a la «barbarie», señala cuál era la piedra angular de los propósitos neoclásicos.

Para que triunfaran dichos propósitos, Nicolás Fernández de Moratín no olvida quién es el destinatario de su prefacio, y así continúa con estas palabras: "Quizá vendrá tiempo en que esto se enmiende, que es muy fácil, muy decoroso y muy preciso, y sólo cuesta el mandarlo» (p. 11). He aquí, en la parte final de la dedicatoria de Guzmán el Bueno, una nueva prueba de los vínculos entre política y literatura, por si hiciera falta. Seguramente, recordaba las opiniones, en pro de una censura estética y moral, de Cervantes, escritas en el capítulo XIVIII de la primera parte de su Don Quijote, y mencionadas por Blas Antonio de Nasarre: «y aquéllos que las

46. Véase Pedro Álvarez de Miranda, Palabras e ideas: el léxico de la Ilustracion temprana en España (1680-1760), Madrid, Anejos del Boletín de la Real Academia Española, 1992, esp. pp. 418-422.

47. Madrid, Oficina de Joachin Ibarra, 1763, pp. XLIV-XLV. 
componen [las comedias] mirarían con más cuidado y estudio lo que hacían temerosos de haber de pasar sus obras por el riguroso examen de quien lo entiende» ${ }^{48}$.

Leandro Fernández de Moratín heredó las preocupaciones de su progenitor, lo que, entre otras cosas, indica que no resultaba tan fácil «enmendar» el teatro; todavía en 1810 intervendrá el hijo en una comisión

encargada de examinar todas las obras dramáticas originales o traducidas de que haya de componerse el repertorio o caudal de los teatros de Madrid, de contribuir a su mejora y de trabajar en los adelantamientos del arte ${ }^{49}$.

Por tanto, tampoco lo habían conseguido ni don Nicolás ni el duque de Medina Sidonia; incluso, según parece ${ }^{50}$, de poco sirvió Guzmán el Bueno en la consolidación de su amistad. Tampoco pudo obtener el afecto del público.

\section{CRITERIOS DE EDICIÓN}

Transcribo, modernizando la ortografía y la puntuación, la dedicatoria de la editio princeps de Guzmán el Bueno (Nicolás Fernández de Moratín, Guzmán el Bueno, Madrid, Antonio de Sancha, 1777, pp. 2-11). En notas a pie de página amplío los datos biográficos del destinatario del texto y doy la referencia bibliográfica de las citas en latín, que traduzco.

48. Disertación o Prólogo sobre las comedias de España, ed. de Jesús Cañas Murillo, Cáceres, Universidad de Extremadura, 1992, p. 56.

49. Gaceta de Madrid, 1 enero 1811, p. 3; apud Georges Demerson, Don Juan Meléndez Valdés y su tiempo (1754-1817), Madrid, Taurus, 1971, I p. 509.

50. F. Sánchez-Blanco, art. cit., pp. 236-237. 
DEDICATORIA DE GUZMAN EL BUENO,

DE NICOLÁS FERNÁNDEZ DE MORATÍN

\title{
Vestigia Græca
}

Ausi deserere et celebrare domestica facta.

Horat., De arte poetica ${ }^{1}$.

\author{
AL EXCMO. SEÑOR \\ DON PEDRO DE GUZMÁN EL BUENO, \\ DUQUE DE MEDINA SIDONIA, etc., etc., etc. ${ }^{2}$.
}

... Accipe iussis

Carmina copta tuis.

Virgilio $^{3}$.

\section{SEÑOR:}

Pocos autores hallarán la feliz combinación de circunstancias que en mí concurren para ofrecer esta tragedia a V.E. Yo celebro en ella una acción grande y heroica sobre cuantas celebran otras naciones. Yo la dedico a tan legítimo dueño, como es un nieto por línea recta del señor don Alonso Pérez de Guzmán el Bueno, y con esto digo que es al Excelentísimo señor Duque de Medina Sidonia, a un mecenas ilustre, benigno y poderoso. La dignidad y timbres de V.E. son tantos y tan esclarecidos que no necesitan el auxilio de mi pluma para hacerlos saber al mundo, y ellos son materia tan abundante que están provocando aun al ingenio más estéril, pues cuanto los demás poetas han dicho con adulación a sus protectores, se lo podía yo decir a V.E. con verdad tan evidente que desafiaba para la prueba a la misma envidia, que no es la menor felicidad de un escritor. No lo es tampoco el que

1. "Al atreverse a abandonar los pasos de los griegos y a celebrar los hechos patrios", Horacio, Ars poetica, vv. 286-287.

2. Pedro Alonso Pérez de Guzmán Pacheco y Moscoso, duque de Medina Sidonia (Madrid, 1724-Villafranca del Panadés, 1779), casado con Mariana de Silva Álvarez de Toledo, hija de la Duquesa de Alba; autor y traductor teatral. Fue amigo y contertulio de Pablo de Olavide (F. Aguilar Piñal, Sevilla y el teatro en el siglo XVII, Oviedo, Universidad de Oviedo, 1974, p. 149), y «miembro de la Real Academia Española, de la Real Sociedad Vascongada, de la de Sevilla y de la Academia de las Ciencias de Londres" (J. Herrera Navarro, op. cit., p. 354).

3. «Recibe los versos que empecé por tu mandato», Virgilio, Bucólica, VIII, vv. 11-12. 
yo dedique mi tragedia no a un magnate distinguido solamente por su grandeza y su fortuna, sino por su erudición y talento en la poesía, que, a pesar de la moderación de V.E., lo publicarán por mí:

Sola Sophocloeo tua carmina digna cothurno ${ }^{4}$.

Mediante lo cual, nadie mejor que V.E. conocerá el corto mérito de mi tragedia, y ésta es la única circunstancia que no es feliz por parte del escritor; pero también me consuela el que V.E. apreciará el trabajo, como quien sabe lo que es, y disculpará los errores. Los crítico-poetas teóricos que en su vida han hecho un verso, y sin la práctica se creen jueces suficientes en un arte tan difícil, por sólo haber leído una o mil Poéticas, censurarán según costumbre; y yo respondo, que siempre que se me dé razón sólida, enmendaré el error, agradeciendo el aviso; pero, no siendo así, ¿qué autor que escribe con principios ha de estimar los diversos e infundados caprichos de sus lectores? Esto no es decir que no habrá defectos, pero, si la obra en común tuviese mérito, ya se sabe que aquéllos, no siendo enormes, se deben disimular, según Horacio y Longino y la razón: ni todos lo que parecen errores lo son en la realidad, pudiéndose interpretar las cosas de mil maneras. Por no reparar en esto, juzgaron algunos críticos que en mi Hormesinda hice crédulo a Pelayo, como si la verosimilitud dramática fuera lo mismo que la física, o como si una tragedia fuera algún pleito ordinario, o un teatro un tribunal. Si observasen a los griegos y a los mejores modernos, encontrarían mi disculpa.

Muchos apoyan su crítica con la naturaleza: el argumento es excelente, pero ella no tiene los límites tan bien señalados que se distingan por líneas para saber cuándo se rompen; y así, en no siendo un absurdo, es imposible conocerlo, pues, según los varios genios, uno juzga natural lo que a otro le parece violento, y las más veces proviene de que leen a sangre fría lo que el poeta escribió encendido y muy agitado, y son pocos los que pueden imaginar las situaciones sublimes y hacer con viveza en su fantasía lo que llaman composición de lugar; pero a cualquiera le es muy fácil murmurar de todo lo que él no hace, reparar en quisquillas gramaticales y hablar donde no le oye el autor. Pero lo más es que muchos errores que verdaderamente lo son, los cometen los autores dramáticos con pleno conocimiento, cuando son muy teatrales, quiero decir, cuando de ellos resultan mayores hermosuras que de la exactitud árida y escrupulosa que prescriben las reglas, las cuales debe creerse que las sabrá cualquier poeta juicioso, por lo menos

4. "Tus composiciones, las únicas dignas de parangonarse con el coturno de Sófocles", Virgilio, Bucólica, VIII, v. 10. 
tan bien como sus críticos, y que para haberlas abandonado en parte (que en lo esencial no es posible) no le habrán faltado motivos, porque las reglas del arte, como tampoco las leyes, no pueden prevenir todos los acasos, y esta interpretación y modificación de unas y otras para la práctica es don privativo de los hombres grandes en ambas facultades.

La observancia de las tres unidades, a pesar de los poetas libertinos, no hay duda que es esencial, pero debe de ser tan difícil que apenas se halla observada con rigor. Yo he procurado que la de acción se reduzca sólo a la resistencia y constancia de aquel heroico español, aunque adornada de varios incidentes a propósito, que la hacen resaltar más y forman los indispensables episodios. La unidad de lugar no está quebrantada, aunque se representa el suceso en el muro y acampamento, porque el auditorio se supone estar en el adarve de Tarifa, desde donde oye y ve cuanto pasa en ambas partes bien contiguas, mayormente considerando el antiguo modo de sitiar las plazas tan diferente del moderno, pues se hablaban unos y otros. Pero es menester tropezar con quien sepa disponer el teatro, y entonces no le faltará verosimilitud ni visualidad. El tiempo empieza a correr ya bien entrado un día de los menores de diciembre, y acaba antes de comer. Bien sé las licencias que se conceden, pero mejor es no usarlas.

El lenguaje he procurado que a lo menos sea español puro, que es mérito en nuestros días, habiéndole corrompido tanto los malos traductores y cultivádole tan poco los que, acaso desconfiados de arribar a la grandeza y sublimidad poco sabida de la lengua castellana, se acogen a la impostura de escribir en otras de que no hay jueces competentes. Pero quien en la suya no es poeta ni retórico, ¿cómo lo ha de ser en otra, que siempre se sabe menos que la materna?, y a ésta se la hace un cierto género de traición en abandonarla por otra. No han hecho así los hombres grandes, que todos lo fueron en la suya, y la castellana tiene tanto que aprender que yo desconfío lograrlo, aunque la estudio continuamente. No se opone esto al estudio de otras lenguas, las cuales deben saberse para otros fines y para enriquecer más y más en lo posible a la materna; pero pensar ser perfectos en las extrañas, además de ser inútil, no es posible, como lo confiesan de buena fe el docto Fleury, D'Alembert y todos los que son sabios ingenuamente. Ejemplos muy respetables tienen los escritores en V.E. y en los elogios que de nuestro idioma hace en su prólogo el serenísimo traductor de Salustio. Si yo no hc conseguido mi fin, será por defecto mío y no de la lengua, que, cultivándola todos, alguno la mejorará.

No hablo de los afectos, situaciones, imitaciones y otras delicadezas del arte, que V.E. verá si están o no practicadas, pues lo sabe ejecutar, pudiéndole yo decir mejor que Ovidio a Cotis, rey de Tracia y gran poeta: 
Haec quoque res aliquid tecum mibi foederis affert

Eiusdem sacri cultor uterque sumus 5 .

Como tal, espero que disimule V.E. mis defectos, y esto me basta para aprobación, que, si yo la logro tan grande, diré:

Nam satis est equitem mihi plaudere, ut audax

Contemptis aliis, explosa Arbuscula dixit.

Horat. Sat. 10. lib. $I^{6}$.

Como la hazaña del señor don Alonso fue tan admirable que aun se emplearon en su elogio muchas plumas extranjeras, como la de Justo Lipsio ${ }^{7}$ y otras, no es mucho que la tratasen ingenios españoles. Algunos dramas he visto de este argumento. Ojalá hubiese acertado a imitar los primores de unos y a evitar los errores de otros, pero quien coteje esta obra con aquellas se desengañará de que en nada se les parece. He procurado guardar el carácter de cada héroe, insinuando algunas fórmulas y costumbres de nuestros abuelos, de las que deseo ser un insigne anticuario, más bien que de otras naciones que poco o nada nos interesan: no sé si es culpable este patriotismo. El amor, que es la piedra de toque de nuestros críticos, es aquí decente, es accesorio y es trágico, que es cuanto hay que responder.

Bien sé que esta tragedia no es para los teatros de hoy día, donde sólo reina la abominación y la barbarie, y no tienen de ello la culpa los ingenios españoles. Quizá vendrá tiempo en que esto se enmiende, que es muy fácil, muy decoroso y muy preciso, y sólo cuesta el mandarlo. Últimamente, señor, yo no podía menos de hacer algún obsequio a la gran casa de Medina Sidonia, ni creí poderla hacer otro, ni éste puede hacérsele mejor; y así, en parte, me desempeño de las muchas obligaciones que confieso deber a V.E., cuya vida ruego a Dios dilate los muchos años que deseo y necesito.

5. «Esto me lleva a una cierta unión contigo: ambos somos adoradores de un mismo culton, Ovidio, Pónticas, II, 9, vv. 63-64.

6. Con la traducción de la pregunta anterior: «[¿Acaso neciamente preferirías que se recitasen tus versos en las escuelas primarias? / Yo no:] pues "me basta que un caballero me aplauda", como dijo la osada Arbúscula», Horacio, Sátiras, I, 10, vv. [75-]76-77.

7. Justus Lipsius, nombre latinizado de Joost Lips, fue un humanista flamenco (1547-1606), que se carteó con Arias Montano, Quevedo, etc. y que, desde su catolicismo neoestoico, alabó a Guzmán el Bueno. 